\title{
Perovskite solar cells: recent progress and future prospects
}

\author{
O. I. Shevaleevskiy \\ Solar Photovoltaic Laboratory, Emanuel Institute of Biochemical Physics, Russian Academy of Sciences, \\ Kosygin St. 4, Moscow, 119334, Russia \\ shevale2006@yahoo.com
}

PACS 73.63.Bd

DOI 10.17586/2220-8054-2020-11-6-716-728

\begin{abstract}
Nanotechnologies and nanostructured materials are attracting significant attention as most promising candidates for achieving drastic improvement of solar energy conversion efficiency in next-generation nanostructured-based perovskite solar cells (PSCs). In this review, we focus on the latest achievements in construction of efficient PSCs and describe new trends in perovskite solar photovoltaics including the development of high-performance perovskite-silicon tandem solar cells, inorganic PSCs with stabilized efficiency and a new generation of PSCs for low lighting conditions that opens great possibilities for indoor applications. A special attention is paid also to the development of new types of efficient photoelectrodes for PSCs based on very large band gap metal oxides.
\end{abstract}

Keywords: nanostructures, nanotechnologies, perovskite solar cells, $\mathrm{ZrO}_{2}$, thin films, semiconductors, tandem solar cells.

Received: 3 August 2020

Revised: 23 August 2020

\section{Introduction}

Nanotechnologies and nanostructured materials are attracting significant attention as most promising candidates for achieving drastic improvement of solar energy conversion efficiency in next-generation nanostructured solar cells (SCs) $[1,2]$. In recent years, considerable interest has beenfocused on a new generation of inorganic-organic metal halide perovskite solar cells (PSCs).

The first report on anew type of PSC with $3.8 \%$ efficiency emerged in 2009 [3]. In this study perovskites were used as sensitizers in Gratzel-type dye-sensitized solar cells (DSCs) [4,5]. In short order, the efficiency of PSCs was increased up to $6.5 \%$ [6]. However, the application of liquid electrolyte in the hole-transporting material (HTM)created a situation in which the stability of SCs was weak and the future of such type of perovskite DSCs looked questionable [6]. Serious progress was gained with the emergence of solid-state PSCs where perovskite material $\mathrm{MAPbI}_{3}$ was spin-coated on nanostructured $\mathrm{TiO}_{2}$ photoelectrode. The PSC n-i-p junction configuration was then accomplished by coating the molecular spiro-MeOTAD HTM film and Au back contact [7]. During short period of time the power conversion efficiency (PCE) of such cells has been dramatically increased and the best cell efficiency has now reached $25.5 \%$ [8,9]. Thus, the above-mentioned achievements in PSC solar photovoltaics have made these devices nearly as efficient as the best conventional SCs based on crystalline silica (c-Si).

In the meantime, the construction of solid state PSCs comprise organic-inorganic hybrid perovskite materials, like $\mathrm{ABX}_{3}$, where $\mathrm{A}$ is an organic cation such as methylammonium (MA+), $\mathrm{B}$ is $\mathrm{Pb}^{2+}$ and $\mathrm{X}$ is $\mathrm{Br}$, or I [10]. The main problem of perovskite materials appeared to be due to their organic nature possessing poor stability when exposed to heat, oxygen and moisture and also due to their rapid degradation under illumination [11-13]. To overcome the stability problems a number of solutions have been proposed [14,15]. However, the long-term stability of PSCs still does not meet the necessary requirements for large scale production. While the stability remains a major problem to be overcome, many other aspects of PSCs are now investigated. In this short overview, attention is given to the latest achievements in constructing more efficient photoelectrodes for PSCs and also to the new trends in perovskite-based photovoltaics associated with the development of high performance tandem PSC-based SCs and a new generation of PSCs for low lighting conditions that opens great possibilities for indoor applications.

\section{Current status of solar photovoltaics}

The key challenge facing the global energy industry is the transfer towards resource-saving technologies and the large-scale introduction of renewable energy sources. Among all the available renewable energy resources, the greatest potential is for that ofsolar radiation energy, which can be directly converted into electricity using solar cells (SCs). The global production of dominant silicon solar panels (mainly monocrystalline (c-Si) and polycrystalline (multi-Si) is exponentially growing, and their cost is declining and currently stands at $\$ 0.21-0.35 / \mathrm{W}$ [16]. Silicon solar cells have a number of undoubted advantages, including long-term stability and high efficiency when working under high 
intensity AM1.5G lighting conditions. Fig. 1 illustrates the exponential growth in global solar panel production during the recent decades and the parallel drop in the cost of silicon solar panels. Long-term forecast of changes in the average cost of electricity generated in the world by silicon solar panels assumes that after 2020, the cost of kWh of electricity, received from the solar cells, will approach the cost of electricity obtained from conventional sources (coil, gas, oil), which will mean the achievement of grid parity.
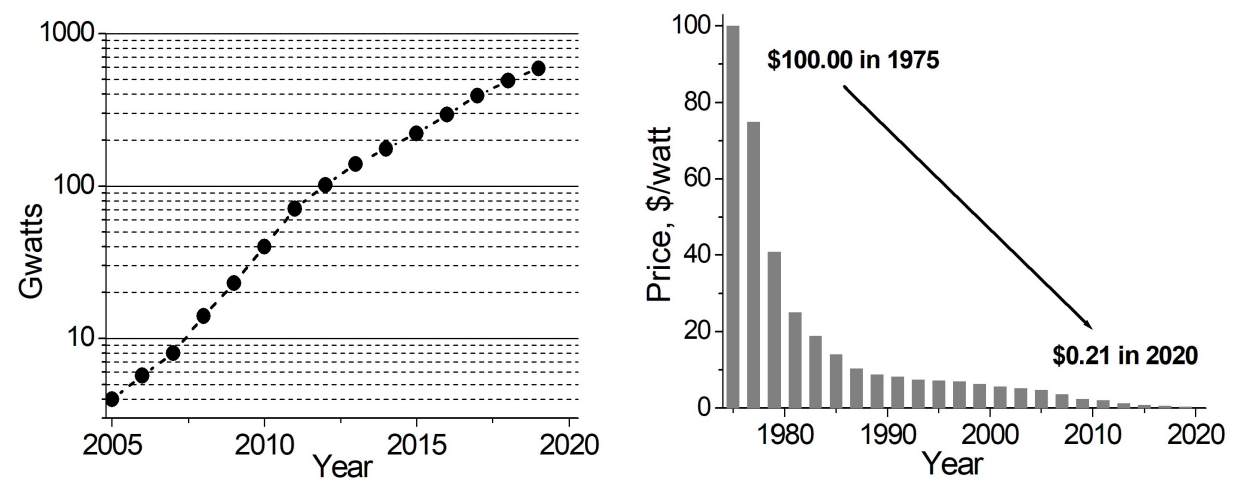

FIG. 1. Illustration of the exponential growth of world installed solar energy capacity (left) and the dramatic drop in the cost of solar PV modules (right)

Other less common types of solar cells, mainly thin-film, which in the last decade have been claimed as potential competitors to Si-based SCs, include solar cells based on amorphous and micromorphous silicon, SCs based on thin chalcogenide films (CIGS), and SCs based on cadmium telluride (CdTe). To date, these technologies totally occupy about $5 \%$ of the global annual solar panels production, and no significant changes are expected in this distribution. Returning to the question of grid parity, it should be noted that for solar photovoltaics, achieving sustainable grid parity can lead to significant changes not only in this industry, but throughout the whole global energy sector. It is worth mentioning that the level of such parity can vary significantly depending not only on the geography of the region, but also on the features of its economic development and energy policy. However, despite the "exponential" achievements of recent decades, the current situation in the field of solar photovoltaics is not so inspiring. The main problem of photovoltaics lies in impossibility of further improvement, most importantly, costs reduction for silicon solar panels, since the potential for the further decline in costs for this technology is greatly limited. In this respect, the scientific community needs to establish new approaches which would allow, based on basic research or through the use of new designs and materials, to create alternative types of SCs, which could provide the grid parity in the majority of world regions and fundamentally change the global energy structure. If we analyze the work of the majority of scientific teams in the field of solar photovoltaics throughout the world, it becomes obvious that the research aimed at the development of the novel SC types is the most relevant currently.

\section{Current status of perovskite solar cells}

The perovskite material, used in conventional solid-state PSCs, such as $\mathrm{CH}_{3} \mathrm{NH}_{3} \mathrm{PbX}_{3}$ demonstrates a tunable band gap ranging from 1.5 to $2.3 \mathrm{eV} \mathrm{[17]} \mathrm{and} \mathrm{possesses} \mathrm{high} \mathrm{light} \mathrm{absorption} \mathrm{coefficient} \mathrm{suitable} \mathrm{for} \mathrm{solar} \mathrm{photovoltaic}$ applications [18]. At the same time, perovskite materials are low-cost while fabrication methods for PSCs have a number of advantages over fabrication process of conventional c-Si solar cells. PSC's architecture comprises a mesoscopic layer of metal-oxide nanoparticles on a conductive substrate, which plays a role of the electron-conductive photoelectrode, a perovskite $\left(\mathrm{CH}_{3} \mathrm{NH}_{3} \mathrm{PbI}_{3}\right)$ layer deposited on top of the photoelectrode, a hole-conductive layer and a metallic counter electrode [19]. The illustration of the PSC architecture and the laboratory samples of PSC devices prepared in the Solar Photovoltaic Laboratory (IBCP RAS, Russia)is given in Fig. 2.

The initial meaning of "perovskite" was about the crystal structure of calcium titanate, which was discovered in 1839 by Gustav Rose and was named by the Russian mineralogist Lev Perovski. Since then, the term "perovskite" has referred to all compounds with the same crystal structure as calcium titanate [20].

The first perovskite-based solar cell construction was reported by T. Miyasaka one decade ago [3]. This device used a liquid electrolyte as an s hole-transporting material (HTM) and have shown poor stability. Later, N. Park et al. [6] improved the PSC efficiency but the problem of the instability was not solved. The situation has changed dramatically with the appearance of solid-state $\operatorname{HTM}(2,20,7,70$-tetrakis(N,N-di-pmethoxyphenylamine)-9,90-spirobifluorene, i.e., Spiro-OMeTAD). They succeeded in the improvement of the device stability and reached an efficiency of $10.9 \%$ 

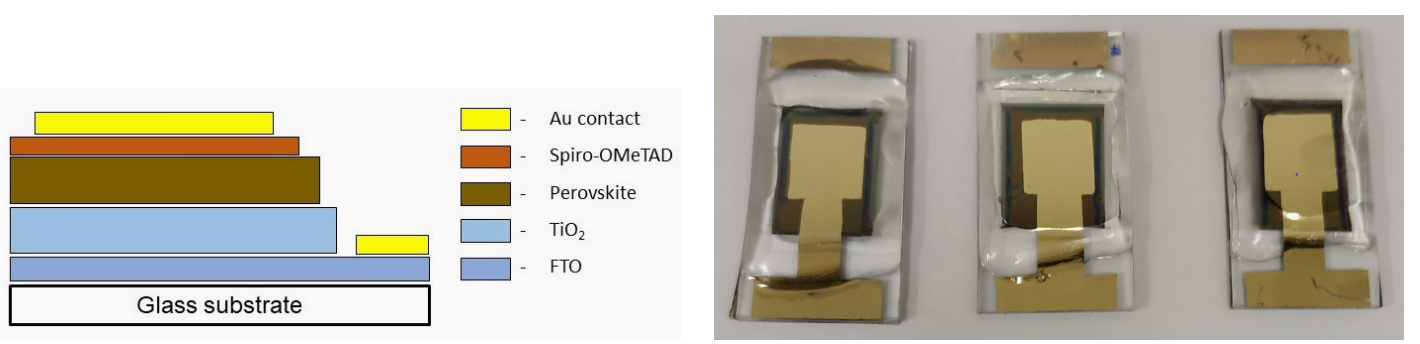

FIG. 2. Device architecture of the PSC (left) and the laboratory PSCs prepared in the Solar photovoltaic laboratory of IBCP RAS (right)

with an open-circuit voltage higher than $1.1 \mathrm{~V}$ [6]. Even better results were obtained in 2013 with the introduction of graphene nanoparticles into PSCs which increased the efficiency up to $15.6 \%$ [21]. In 2015, a new record of $20 \%$

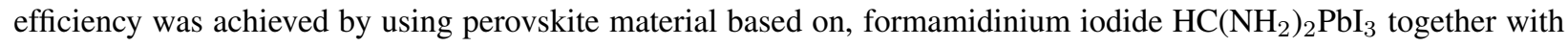
poly-triarylamine (PTAA) HTM [22]. Finally, in 2017, the record efficiency of $22.1 \%$, was reported [23]. At the same time, perovskite-based tandem cells with c-Si bottom cell with the efficiency of $26.7 \%$ appeared [24]. Very recently Oxford PV declared $28.0 \%$ efficiency tandem perovskite-silicon solar cell while Helmholtz-Zentrum Berlin (HZB) announced a certified efficiency of $29.15 \%$. However, in both cases, no scientific publications have yet appeared.

The efficiency progress of PSCs in comparison with other photovoltaic devices is discussed in [25]. Perovskite solar photovoltaics, as compared to other photovoltaic technologies, including thin film CIGS, organic SCs, DSCs and a variety of Si-based devices, aims to become the best alternative to solar photovoltaics of the future.

\section{PSC research history}

Currently, one of the most promising areas of basic research in the field of photovoltaics is the development of perovskite solar cells (PSCs). Perovskite materials have a unique structure in which organic and inorganic components are alternating. That is what causes the presence of perovskite unusual electrical, magnetic and optical properties. First solar cells sensitized with perovskites have been presented in the article of T. Miyasaka (Tokyo, Japan) in 2009 in which the chemical compound using $\mathrm{CH}_{3} \mathrm{NH}_{3} \mathrm{PbI}_{3}$ (band gap $1.55 \mathrm{eV}$ ) in combination with a liquid electrolyte reached the energy conversion efficiency of $3.8 \%$ [3]. Later, through the optimization of the surface of the titanium dioxide and the further processing in the laboratory perovskite N. Park (Suwon, South Korea) in 2011 managed to get the efficiency value of $6.5 \%$ [6]. However, the fabricated cells worked poorly as perovskites decomposed by contact with sodium iodide/triiodide ions. In this regard, in 2012 M. Gratzeland, H. Park (Lausanne, Switzerland) proposed to use an organic semiconductor Spiro-MeO-TAD as a hole transporter [11]. The efficiency of sunlight conversion was increased to $8-10 \%$. Thus, there was a transition from the standard solar cells working in conjunction with liquid electrolyte for solid state solar cells. In 2013, M. Gratzel and coworkers have shown that nanocrystals sequential deposition precursors $\left(\mathrm{CH}_{3} \mathrm{NH}_{3} \mathrm{PbI}_{3}\right.$ and $\left.\mathrm{PbI}_{2}\right)$ solution on the surface of mesoporous titanium dioxide can effectively control the morphology of the applied perovskite layer $\mathrm{CH}_{3} \mathrm{NH}_{3} \mathrm{PbI}_{3}$ [26]. Maximum efficiency of thus obtained solid solar cell based on mesoscopic layers of titanium dioxide was $15 \%$. The research team, headed by Snaith (Oxford, UK) has proposed a way to create PSCs [7]. Based on the results obtained, they published a paper in 2012, according to which, the replacement in the solar cell layer of mesoporous titanium dioxide similar in structure to the insulating layer of aluminum oxide voltage not only changed, but also increased. This indicates that the perovskite has $\mathrm{CH}_{3} \mathrm{NH}_{3} \mathrm{PbI}_{3}$ intrinsic conductivity, while it can move in both electrons and holes, i.e. ambipolar material has such properties. Referring to ambipolar properties perovskites in $2013 \mathrm{H}$. Snaithand colleagues (Oxford, UK) developed solid-state solar cell with a heterojunction type "pin", which takes the role of an active layer of perovskite layer disposed between the dense titanium dioxide layer (n-type) layer and Spiro-MeO-TAD (p-type) [27]. The mesoporous titania layer was absent, as perovskites, which are synthesized by mixing $\mathrm{PbI}_{2}$ and $\mathrm{CH}_{3} \mathrm{NH}_{3} \mathrm{PbI}_{3}$ in $\gamma$-butyrolactone, were deposited by vapor deposition. In this case, the conversion efficiency of solar energy into electric energy reaches $15.6 \%$ [21]. After the scientific papers mentioned above, from 2013 to the present day, a large number of publications have emerged devoted to finding ways to improve the efficiency of solar cells based on perovskites. For example, in early 2015, M. Gratzel and colleagues suggested before application to the mesoscopic layer of titanium dioxide added to the solution of the perovskite in a mixture of $\gamma$-butyrolactone and dimethylformamide (DMF) 4-butylphosphonic acid 4-ammonium chloride. This additive acts as a crosslinker formed on the surface of the electrode grains of perovskite structures by means of hydrogen bonds between $-\mathrm{PO}(\mathrm{OH})_{2}$, and $-\mathrm{NH}_{3}$ groups that facilitates penetration of the particles into the pores $\mathrm{CH}_{3} \mathrm{NH}_{3} \mathrm{PbI}_{3}$ titanium dioxide and provides a more uniform layer of the light absorber. The 
efficiency of the solar cell, created in accordance with this methodology, reached $16.7 \%$ [28]. In 2014, S. Seok and colleagues (Daejeon, South Korea) conducted research of perovskite mixed composition $\mathrm{CH}_{3} \mathrm{NH}_{3} \mathrm{~Pb}\left(\mathrm{I}_{1-x} \mathrm{Br}_{x}\right)_{3}$. It has been found that the partial replacement of iodide ions, bromine ions $(x=0.1-0.15)$ increases the stability of the desired material. In such a PSC, where poly-triarylamine was used as a hole carrier, the efficiency reached 16.2\% [29]. In the same laboratory, mixed perovskites of $\gamma$-butyrolactone and dimethyl sulfoxide (DMSO) were synthesized and twice applied on a mesoscopic titania layer. Wherein the second time toluene was added to the solution recommended perovskite. By this the most uniform and dense layers of absorbent material were obtained [29]. At the end of 2014 S. Seok (Daejeon, South Korea) used a more complex structure of perovskite, containing methylammonium ions and formamidine as a sensitizer, achieving an efficiency of $17.9 \%$. This result was certified in a photovoltaic calibration laboratory, and was the highest for that time [10]. Perovskite $\mathrm{HC}\left(\mathrm{NH}_{2}\right)_{2} \mathrm{PbI}_{3}$ used was characterized by band gap $(1.47 \mathrm{eV})$ which was more narrow than in $\mathrm{CH}_{3} \mathrm{NH}_{3} \mathrm{PbBr}_{3}(2.0 \mathrm{eV})$. In 2015, in the laboratory of H. Park (Seoul, South Korea), they have established more than 40 samples of PSCs, which amounted to an average efficiency of $18.3 \%$, with the maximum efficiency equal to $19.7 \%$ [30]. In later works, by optimizing the design of a device architecture with a precise controlling of the perovskite grains and grain boundaries, a power conversion efficiency of $22 \%$ was achieved [31]. The research group of S. Seok (Daejeon, South Korea) has provided the compositional engineering of low band gap formamidinium lead iodide based layers, $\left(\mathrm{FAPbI}_{3}\right)_{1-x}\left(\mathrm{MAPbBr}_{3}\right)_{x}$, which allowed the synthesis of a more stable microstructured dense layers of efficient PSCs [32,33].

In recent years, the possibility of using PSCs in tandem was actively studied [34]. Different types of solar cells may be combined with each other either mechanically (i.e., when they are simply connected to contacts), or monolithically configured, when both cells are combined into one monolithic device and between them there is an additional layer of conductive material. The efficiency of first tandem solar cells was $18.7 \%$ [35]. Tandem solar cells based on perovskite with a silicon element in a monolithic configuration was shown to achieve the efficiencies exceeding $25 \%[36,37]$. The advantages of using perovskites as sensitizers in solar cells are obvious. First, they absorb light across a wider range than those solar cells with dyes in a liquid electrolyte (in DSCs) used to date and secondly, they have ambipolar characteristics, and thirdly, they are cheap and lead to efficiencies exceeding $20 \%$. However, there are some unsolved problems to date [34,38]:

1) Perovskites are unstable and degrade by prolonged exposure to sunlight;

2) Lead ions that are part of perovskites, are highly toxic;

3) PSCs are characterized by a strong hysteresis in the measurement of current-voltage characteristics in forward and reverse modes;

4) Creating PSCs with a large area is complicated;

5) Stability problems and the development of inorganic PSCs.

As it was previously mentioned, for a short period, the efficiency of laboratory scale PSCs increased from $3-5$ to $20-24 \%$, which made them competitive with conventional Si-based SCs and the most promising candidates for solving the problems of global photovoltaics. However, it soon became apparent that the key component of the PSC the photoactive absorber layer of perovskite material $\mathrm{CH}_{3} \mathrm{NH}_{3} \mathrm{PbI}_{3}$ - was structurally unstable under conditions of ambient humidity, light exposure, and rapidly and noticeably degraded under increased temperatures. Studies have shown that under real outdoor conditions, the efficiency of $\mathrm{MAPbI}_{3}$-based PSCs decreases to zero over a short period of time [39]. As a result, the main photovoltaic parameter of the PSCs, i.e. stabilized efficiency, remains uncompetitive with respect to Si-based SCs hich possess high long-term stability.

Since the problem of achieving the long-term stability of conventional PSCs remains unresolved, in the past few years attempts have been made to replace classical organo-inorganic materials in PSCs with inorganic systems based on lead halides with perovskite structure of $\mathrm{APbX}_{3}$ type, where $\mathrm{A}$ is an inorganic cation, and the anion is $\mathrm{PbX}_{3^{-}}(\mathrm{where}$ $\mathrm{X}=\mathrm{Cl}, \mathrm{Br}, \mathrm{I})$. In this respect, the works carried out by the scientific team headed by P. Troshin (IPCP RAS, Russia) attract a considerable attention. In their studies, perovskite materials were used with the structure of $\mathrm{CsPbI}$, which showed significant advantages in terms of stability of the photovoltaic parameters being introduced in PSCs [40, 41]. Similar investigations have been carried out in the world most recognized photovoltaic research group NREL (NREL, USA), where high efficiency values were achieved in such PSCs [42]. At the same time, a number of studies indicate that the proposed compounds based on lead halides could be unstable over prolonged periods. The latter may happen due to the high diffusion ability of halogen atoms and their high ionic mobility, which could be initiated by temperature and photoeffects and as a result can lead to structural changes in the crystal lattice of halogen-containing compounds.

\section{Inorganic PSCs based on complex oxides}

Recently, compounds with the general structure $\mathrm{A}_{2} \mathrm{~B}^{\prime} \mathrm{B}^{\prime \prime} \mathrm{O}_{6}$, which are double oxide perovskites of rare-earth elements $-\mathrm{R}_{2} \mathrm{NiMnO}_{6}(\mathrm{R}$ is a rare-earth element), have attracted special interest [43-47]. Unique semiconductor and 
optical properties were found for $\mathrm{Sm}_{2} \mathrm{NiMnO}_{6}$ (SNMO). Its high dielectric constant helps to reduce the recombination rate of electron-hole pairs and the optical band gap $\left(E_{g}=1.4 \mathrm{eV}\right)$ corresponds to the maximum of the solar radiation spectrum. Both of these parameters are critical for the effective operation of photovoltaic converters $[48,49]$. One of the main advantages of this class of compounds is that such inorganic systems, a priori, have high long-term stability under various temperature conditions, the absence of photodegradation and resistance to atmospheric humidity. Complex oxides with a double perovskite structure have the optical absorption range close to that of the solar spectrum and high photoconductivity. The optical band gap values $E_{g}$ are in the range of $2-2.5 \mathrm{eV}$, and with doping, could be varied to $1-1.5 \mathrm{eV}$. Attempts to use such compounds for the fabrication of PSCs led to relatively low efficiencies of photoconversion, however, comprehensive fundamental and engineering efforts in this area have not yet been undertaken. At the same time, preliminary studies carried out in several world laboratories have shown promising opportunities for optimizing the design of PSCs based on these compounds and improving their photovoltaic parameters, which opens up the possibility of developing a new class of PSCs with high long-term stability.

To conclude, perovskite photovoltaics currently plays a significant role in the field of solar cell research. Many hundreds of laboratories across the world are specialized in this field and their number is constantly growing. Analysis of research activities by competing groups within the perovskite photovoltaics area shows that the studies could be divided into three groups in accordance with the type of photoactive materials used for PSCs fabrication. The largest group studies the conventional organic-inorganic PSCs based on $\mathrm{CH}_{3} \mathrm{NH}_{3} \mathrm{PbI}_{3}$ or similar (mixed cation and/or mixed halide) perovskite structures. The smaller second one is focused on the development of more stable inorganic PSCs with $\mathrm{APbX}_{3}$ structure, where $\mathrm{A}$ is an inorganic cation. Finally, the main activities of the third group are related to the studies aimed at the development of highly stable inorganic perovskite-type rare-earth oxides (e.g. $\mathrm{Sm}_{2} \mathrm{NiMnO}_{6}$ ) and their photovoltaic applications [45].

\section{Perovskite cells for indoor photovoltaics}

\subsection{Emerging of photovoltaics for low-intensity sources}

Decades ago, when only Si-based SCs dominated in solar photovoltaics, efforts were provided to fabricate perfect and efficient devices for application under indoor low-intensity illumination. Silicon SCs have a number of definite advantages, including long-term stability and high efficiency when working under standard conditions AM1.5G $\left(1000 \mathrm{~W} / \mathrm{m}^{2}\right)$. However, it was shown that the efficiency of c-Si SCs decreases at low levels of solar radiation and significantly decreases under diffuse lighting conditions [50]. Fig. 3 shows the effects of light intensity and incidence light angle on the efficiency for DSC and c-Si solar cells. A similar behavior, somewhat less pronounced, was observed for other types of conventional, but less common solid-state PCs based on amorphous silicon (a-Si:H) and chalcogenides (CIGS). In this regard, one of the relevant tasks of modern photovoltaics is the search for alternative types of PCs, effective both in high solar radiation conditions and under low-intensity and defused light fluxes.
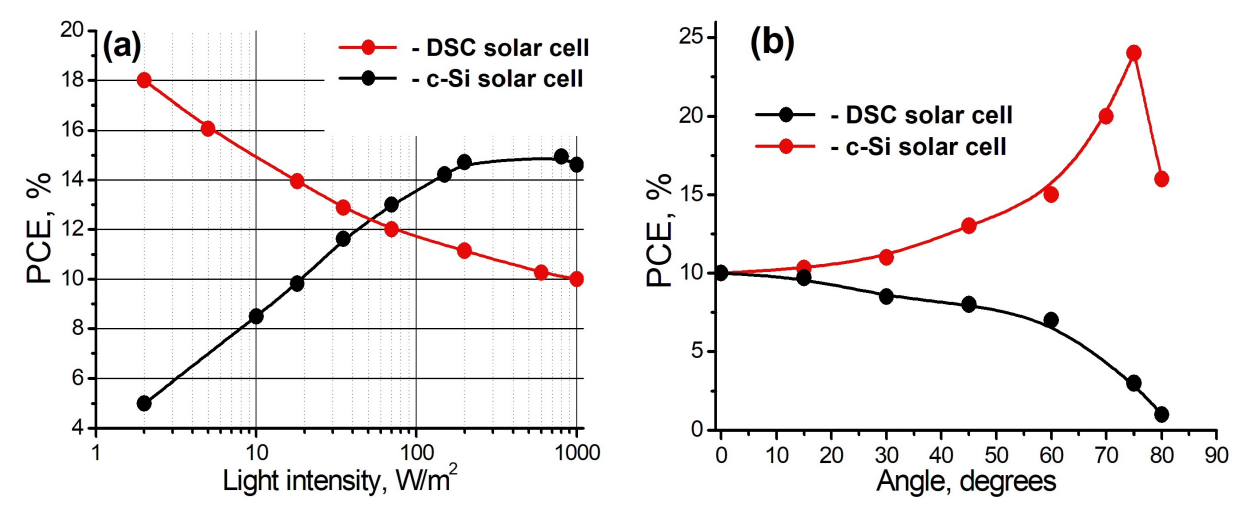

FIG. 3. Comparison of the effects of light-intensity (a) and incidence light angle (b) on the efficiencies of DSC and c-Si solar cells

Perovskite cells for indoor photovoltaics looks to promise a significant future for local power generation [51]. Fig. 4 illustrates the difference in the behavior of PCE dependence on light intensity for PSC and c-Si solar cells. It was also shown that PSCs can efficiently convert waste lighting from different artificial sources into electric power. Perovskite photovoltaic cells are highly efficient and cost-effective. Recently, it was shown that stoichiometry-controlled perovskite-based photovoltaic cells illuminated under the dim light-emitting diode (LED) are highly effective and provide unusually large PCE. It was found that $10 \%$ bromide-doped perovskite photoactive layers exhibit the best 
performance as a result of better crystallization and uniform surface that helped to form larger grains of perovskite with reduced defect concentrations, which suppressed carrier trapping and recombination and resulted in improved PSC performance [53]. As a result, under dim LED indoor illumination of 1000 lx, these types of PSCs have gained PCE of $34.5 \%$ [54]. Actually, the result obtained demonstrates the appearance of the new indoor electronics.

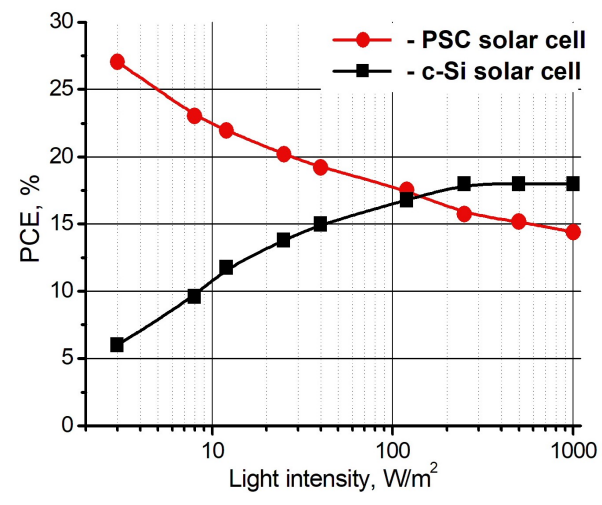

FIG. 4. Dependence of power conversion efficiency (PCE) on light intensity for PSC and c-Si solar cells

Two new rapidly developing areas have emerged recently as a part of global energy trends. One of them is related to the development of the Internet of Things (IoT) environment and the upcoming need for off-grid power for a large number of electronic devices with low power consumption. Another one, called "energy harvesting" ("collection by crumbs"), still not directly intersecting with the first, is the development of the low-power collecting systems from various energy sources. Photovoltaic devices that do not need to be replaced, which should be adapted to work in ambient lighting conditions, are considered as ideal candidates for indoor light harvesting and powering the IoT devices. As was shown above, there is no practical prospects in using the traditional solar cells based on crystalline silicon or chalcogenides for this purpose.

Application of PCs for efficient indoor light harvesting could be carried out by adapting solar cells based on organo-inorganic compounds, in which the absorption spectrum of photoactive materials more closely matches the spectral characteristic of radiation from the artificial light sources. Dye-sensitized solar cells (DSCs) and perovskite solar cells (PSCs) could be regarded as the most promising candidates for this purpose. It has been shown that in DSCs the efficiency increases as the illumination decreases from $10-12 \%$ in AM1.5G mode to values exceeding $20 \%$ under diffuse artificial lighting (200 - $1000 \mathrm{~lx})$. Under similar conditions, PSCs demonstrate even more impressive results when the efficiency increases from $\sim 18-20 \%$ in AM1.5G mode to $\sim 30 \%$ under $200-1000$ lx ambient lighting [51, 53, 54].

\subsection{Nanocrystalline solar cells performance under variable outdoors illumination}

In recent years efforts have been focused on the development of DSC and PSC solar cells for efficient operation under both high solar radiation during sunny days and under low-light conditions in cloudy weather. It was found that under the diffuse lighting conditions in cloudy weather, DSCs and PSCs remain the only really functioning types of solar photoconverters. The data obtained indicated that the efficiency for either PSCs or DSCs in outdoor conditions demonstrated an increase in conversion efficiency with a decrease in light intensity. The data available from the literature have shown great promise for the use of DSC- and PSC-based light energy SCs for highly efficient indoor operation under low-power artificial light sources with a relatively narrow spectral range [50,54]. Thus, increase in the efficiency and development of novel stable photoconverters based on DSC and PSC, optimized for indoor operation under diffuse artificial lighting, is a new and relevant problem for modern photovoltaics.

In the field of basic research, regarding the processes of light energy conversion in DSC and PSC, optimized for operation in a specific spectral range of artificial lighting, it becomes necessary to address a number of poorstudied issues related to the specific energic characteristics of interfaces under conditions of predominant absorption of photons with energies ranging from $2.5-3 \mathrm{eV}$ (solar cells are illuminated outdoors by the solar spectrum in the range of $\sim 0.6-3.5 \mathrm{eV}$ ). Another important aspect is that the light fluxes and therefore the number of photogenerated charge carriers when operating under ambient lighting conditions are about 3 orders of magnitude lower compared to the standard AM1.5G mode, which makes it critically important to optimize charge transfer carrier processes of across the interfaces in conditions of low-intensity artificial lighting. In the applied aspect, bearing in mind the lack of direct illumination of the photoconverter surface located indoors, new engineering solutions are required to create 
more efficient SCs designs, for which, in particular, it is possible to use the double-sided PC architecture. Fig. 5 shows an example of such a design realized in a double-sided photovoltaic device for indoor operation under ambient lighting introduced by O. Shevaleevskiy and coworkers (IBCP RAS, Russia) [55]. Development of double-sided SCs architectures for efficient indoor light harvesting opens a possibility to reach outstanding efficiencies. Bearing in mind that with the appropriate location of a PSC with more than $30 \%$ efficiency [54], where low intensity diffuse lighting falls on the PSC surface from all sides, the efficiency of a double-sided photovoltaic device can be doubled, compared to the one-sided conventional scheme, and could reach the value of around $60 \%$ efficiency per unit area.

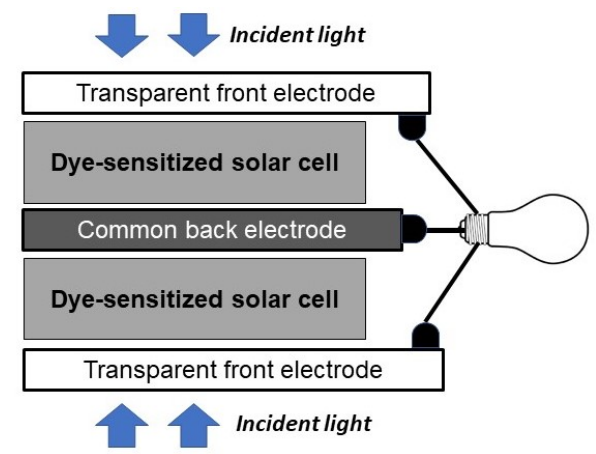

FIG. 5. Architecture of a double-sided DSC solar cell [55]

\subsection{Current status of indoor photovoltaics}

To date, the world production of solar cells, can be conventionally divided into the following categories: solar modules of a large area for powerful solar power plants that generate network electricity, modules for distributed systems of local consumers, and small-sized systems to power portable electronic devices [54]. In turn, the latter category also includes SCs for low-power autonomous SC devices and systems (energy harvesting) for the application in the enclosed areas under low-intensity artificial lighting. A decade ago DSCs only looked to be the most promising for this purpose, where they demonstrated obvious advantages [56,57]. Unlike conventional SCs, DSCs demonstrated a unique advantage of maintaining high indoor efficiency in low-intensity artificial lighting [58]. Despite the obvious interest in using DSCs for these purposes, there appeared only a few significant publications on DSCs in indoor environments under ambient lighting conditions [59-62]. The main milestone lies in a significant difference between the AM1.5G solar radiation spectrum and the illumination parameters, adapted for indoor work with predominantly artificial light. In the spectrum of the incident solar radiation AM1.5G, almost half of the energy is in the infrared range. However, the limits of spectral absorption in conventional SCs based on crystalline silicon or chalcogenide (CIGS) are located in the region of $1000 \mathrm{~nm}$. The same concerns and PSCs while for both several requirements should be met for efficient indoor operation. Fig. 5 shows the results which demonstrate the remarkable difference between c-Si and perovskite solar cell behavior under varied illumination.

Alternatively, photovoltaic devices for the enclosed areas explores the behavior of the elements in artificial light from the following light sources: incandescent bulbs, fluorescent lamps CFL (compact fluorescent lights) and LED sources [63]. The intensity of the lighting sources when working indoors depends heavily on many factors, including the type of room, the location of the SC, its orientation, etc., which can vary widely from dozens of $\mu \mathrm{W} / \mathrm{cm}^{2}$ to dozens of $\mathrm{mW} / \mathrm{cm}^{2}$ [64]. The intensity of indoor lighting is measured in $1 \mathrm{x}\left(\mathrm{lm} / \mathrm{m}^{3}\right)$ and can be correlated with $P\left(\mathrm{~W} / \mathrm{m}^{3}\right)$ insolation capacity through the appropriate formulas. Typically, artificial light sources with a light flow level of $200-500 \mathrm{~lx}$ or solar simulators with a radiation capacity of $50-5 \mu \mathrm{V} / \mathrm{cm}^{2}$ are used to study and operate SCs indoors. In accordance with the standards established, the minimum lighting values in the office space should be within $200-500$ lx. It is also accepted that the lighting levels of the rooms correspond appropriately to: (1) lowlight $\left(0-200 \mathrm{~lx}\right.$, or $\left.0-180 \mu \mathrm{W} / \mathrm{cm}^{2}\right)$; (2) medium light $\left(200-500 \mathrm{~lx}\right.$, or $\left.180-450 \mu \mathrm{W} / \mathrm{cm}^{2}\right)$, and (3) high light (>500 lx, or $>450 \mathrm{muW} / \mathrm{cm}^{2}$ ). The scope of the ongoing scientific efforts for the constructing PSCs with specific characteristics is directly related to the emerging of new direction in the world, called "Energy harvesting" (also "Energy scavenging"), i.e. collection and accumulation of low-density energy from non-carbon sources, such as sun, wind, thermal, gradient and kinetic energy. The introduction of "Energy harvesting" ideology in the industrial world is aimed at using small amounts of energy (the "small-cut" energy collection) to power electronic devices with low energy consumption, primarily for small low energy wireless standalone devices like sensors, switches, "smart dust" etc. PV energy harvesting is a low-density solar energy collection that combines a combination of technologies to 
generate SC electricity in low-light environments indoors, and as a result of accumulation energy using batteries or supercapacitors. Initially such devices were powered by SCs on the basis of amorphous silicon (a-Si), the effectiveness of which, unlike other types of solid-state SCs, was less dependent on the light intensity. It is important to emphasize that efficiency of a-Si SCs under low lighting conditions does not exceed $4-5 \%$ [65]. Alternatively, DSCs in similar conditions may show 4 times greater efficiency exceeding $20 \%$ while PSCs promise to reach more than $30 \%$ efficiency [54]. It denotes that the required lighting period for powering the indoor electronic device using PSC will be 5 times less than in case of using conventional a-Si SC for this purpose.

\section{New materials for PSC fabrication: efficient nanocrystalline photoelectrodes}

In PSCs, the photoelectrode plays a key role of the electron transport layer, which transfers charge carriers generated by a perovskite layer, absorbing photons, to the back contact of the device. To be effective, the electron transport layer should minimize the recombination processes at the perovskite/electrode interface. While a number of different metal oxides have been examined to find a proper electron transport material for this purpose the best performance was reached using a conventional $\mathrm{TiO}_{2}$ layer $[66,67]$. A sufficient increase of electron transport parameters in $\mathrm{TiO}_{2}$ mesoscopic electrodes can be gained by niobium doping that was first used in $\mathrm{Nb}$-doped $\mathrm{TiO}_{2}$ photoelectrodes for DSCs [68-70]. It was shown that with the increase of $\mathrm{Nb}$ concentration from 0 to $3 \mathrm{~mol} \%$ the conductivity of a nanocrystalline layered $\mathrm{TiO}_{2}$ photoelectrode was also increased [69,71]. Later,a similar behavior was observed in PSCs where the use of $\mathrm{a} \mathrm{TiO}_{2}$ layer doped with $\mathrm{Nb}$ content of $2.7 \mathrm{~mol} \%$, which resulted in $19 \%$ improvement of a power conversion efficiency [72,73]. The transmittance spectra in $\mathrm{Nb}$-doped $\mathrm{TiO}_{2}$ photoelectrodes presented in Fig. 6 have shown a blue shift, which was increased with doping concentration. Thus, the $\mathrm{TiO}_{2}$ band gap increases with doping from $3.0 \mathrm{eV}$ in the undoped sample to $3.2 \mathrm{eV}$ in $2.7 \mathrm{~mol} . \% \mathrm{Nb}$ doped $\mathrm{TiO}_{2}$.

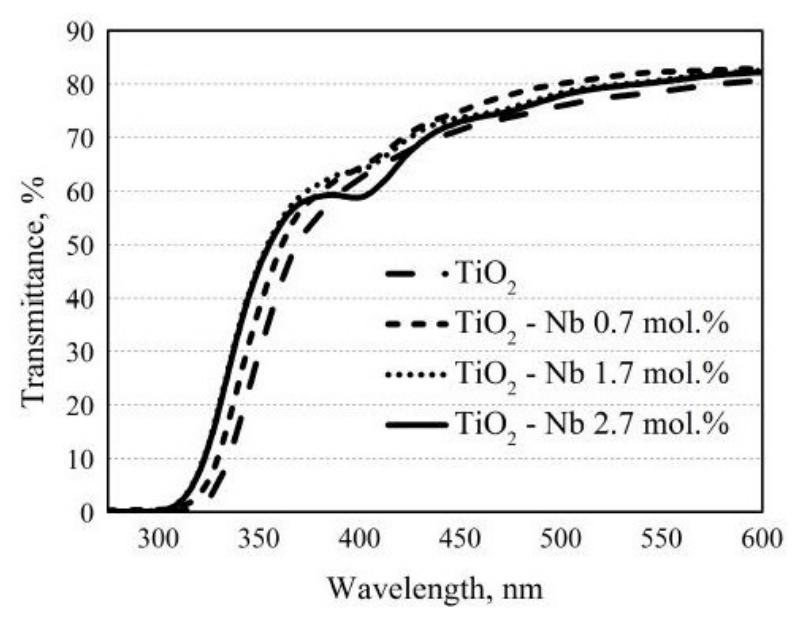

FIG. 6. Optical transmittance of $\mathrm{Nb}$-doped $\mathrm{TiO}_{2}$ layers with varied $\mathrm{Nb}$ content [72]

The new trend of the last few years is the application of very wide-band gap oxides, such as $\mathrm{ZrO}_{2}$, with $E_{g} \sim$ $6 \mathrm{eV}$ [74]. Nanostructured layers based on a very large band gap metal oxides provide effective electron transfer, even when the electron density in the conduction band remains negligible [75]. The effective electron conduction through the nanostructured $\mathrm{ZrO}_{2}$ observed was explained on the basis of the hopping conduction mechanism through localized states within forbidden zone of $\mathrm{ZrO}_{2}$ [74,75]. Fig. 7 shows schematic energy band diagrams demonstrating the energy band structure for PSCs based on a $\mathrm{ZrO}_{2}$ photoelectrode (Fig. 7a) and on traditional $\mathrm{TiO}_{2}$ photoelectrode (Fig. 7b). The band diagram in Fig. 7a demonstrates that the conduction band edge of perovskite has the energy above the conduction band edge of $\mathrm{TiO}_{2}$ photoelectrode that enables a classic photoexcited electron transfer from the conduction band of perovskite layer to the conduction band of a $\mathrm{TiO}_{2}$ photoelectrode [76].

In order to change the optoelectronic characteristics of a $\mathrm{ZrO}_{2}$ it can be doped with yttrium oxide $\left(\mathrm{Y}_{2} \mathrm{O}_{3}\right)$, which peermits a more suitable design for the photoelectrode based on $\mathrm{ZrO}_{2}-\mathrm{Y}_{2} \mathrm{O}_{3}$ nanostructured material [77]. Doping with rare-earth metals was shown to improve the transport characteristics of the photoelectrodes and increased the efficiency of the PSCs. It was recently reported the construction and investigation of PSCs with a device architecture of glass/FTO/ZrO $\mathrm{Zr}_{2}-\mathrm{Y}_{2} \mathrm{O}_{3} / \mathrm{CH}_{3} \mathrm{NH}_{3} \mathrm{PbI}_{3}$ /spiro-MeOTAD/Au, in which the doping content of $\mathrm{Y}_{2} \mathrm{O}_{3}$ in $\mathrm{ZrO}_{2}-\mathrm{Y}_{2} \mathrm{O}_{3}$ was varied from 0 to 10 mol.\% [76].

Figure 8 demonstrates a comparative view of diffuse reflection spectra $(R)$ for undoped $\mathrm{ZrO}_{2}$ and for $\mathrm{ZrO}_{2}-$ $\mathrm{Y}_{2} \mathrm{O}_{3}$ powders where the $\mathrm{Y}_{2} \mathrm{O}_{3}$ content varies from 3 to 10 mol. \%. The $E_{g}$ values for $\mathrm{ZrO}_{2}$ and $\mathrm{ZrO}_{2}-\mathrm{Y}_{2} \mathrm{O}_{3}$ system 


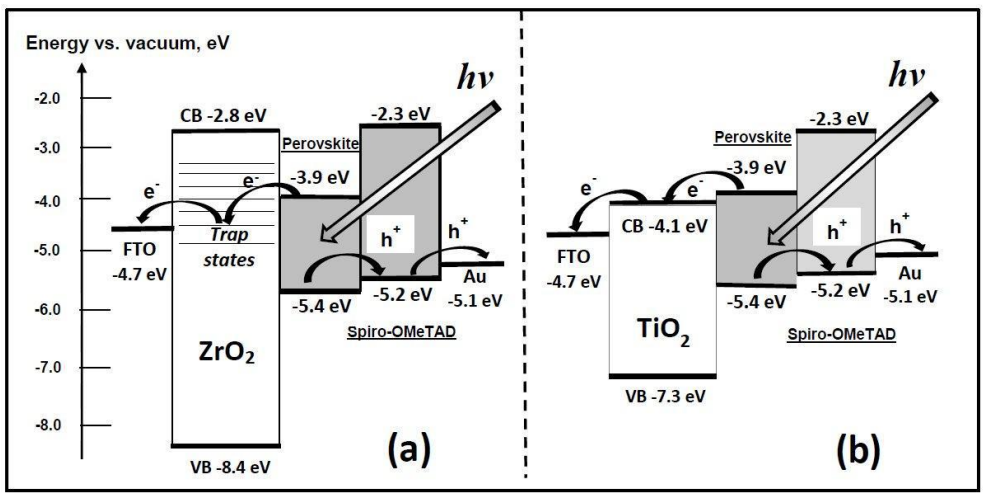

FIG. 7. Schematic energy band diagrams for PSCs based on $\mathrm{ZrO}_{2}$ (a) and $\mathrm{TiO}_{2}$ photoelectrodes (b) [76]

were obtained from the linear extrapolation of $(\alpha h \nu)^{2}$ which revealed that the increase of doping concentration also increases the $E_{g}$ value from $5.74 \mathrm{eV}$ in $\mathrm{ZrO}_{2}$ to $5.63 \mathrm{eV}$ in $\mathrm{ZrO}_{2}-\mathrm{Y}_{2} \mathrm{O}_{3}$ (3 \%) [76].

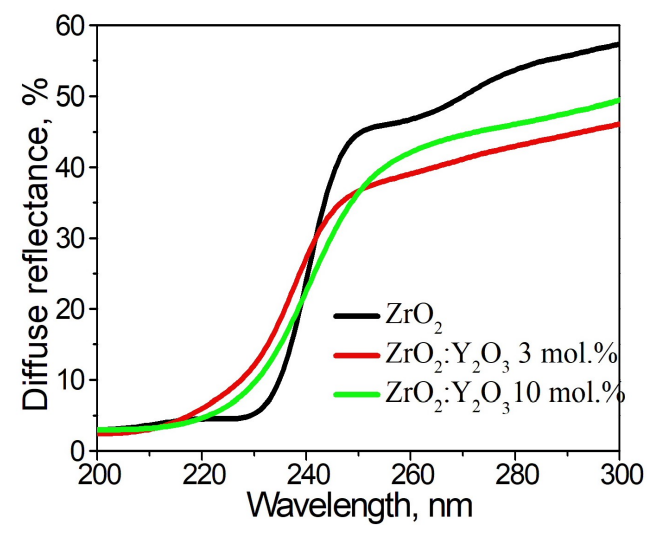

FIG. 8. Diffuse reflectance spectra for the powders of undoped $\mathrm{ZrO}_{2}$ and $\mathrm{ZrO}_{2}-\mathrm{Y}_{2} \mathrm{O}_{3}$ system [76]

Figure 9 presents I-V characteristics, recorded for PSCs under standard illumination conditions AM1.5 G. A comparison between the efficiencies of the PSCs fabricated with pristine and $\mathrm{Y}_{2} \mathrm{O}_{3}$-doped $\mathrm{ZrO}_{2}$ photoelectrodes clearly shows the advantages of the dopped systems which sufficiently increases the short circuit currents and fill factors of PSCs, thus increasing the power conversion efficiencies.

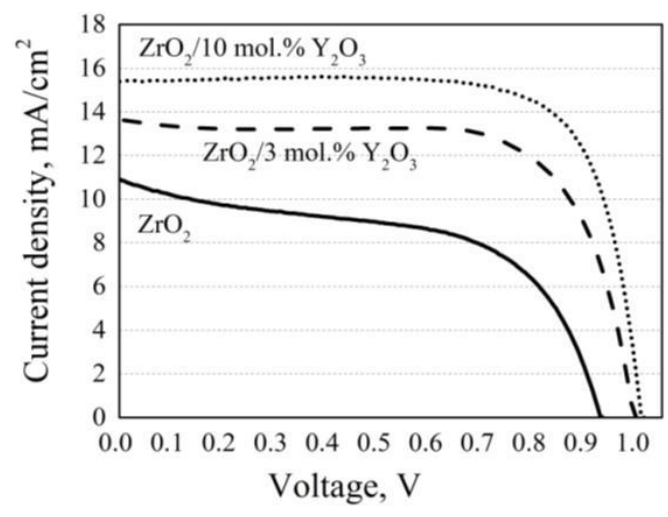

FIG. 9. J-V characteristics of the PSCs based on $\mathrm{ZrO}_{2}-\mathrm{Y}_{2} \mathrm{O}_{3}$ photoelectrodes [76] 


\section{High efficiency tandem PSC/c-Si solar cells}

Initially, tandem configurations with transparent top cells were successfully applied for the design of tandem DSC/c-Si solar cells [79] and tandem DSC/PSC solar cells $[78,79]$. However, in the meantime the most promising design comprise the combination of perovskite and silicon solar cells [81]. Tandem perovskite-silicon solar cell with the optimized design of the perovskite top cell and c-Si bottom cell reached certified efficiencies of 26.7 \% [24]. Very recently Oxford PV declared $28.0 \%$ efficiency tandem perovskite-silicon solar cell while Helmholtz-Zentrum Berlin (HZB) announced a certified efficiency of $29.15 \%$. However, in both cases no scientific publications appeared to-date.

Here, we focus on the structural adjustment of the top cell based on the structural evolution of perovskite/silicon tandem solar cells to improve their performance [81,82]. To date, c-Si-based SCs under AM1.5G lighting conditions have demonstrated an efficiency greater than $25 \%$, but it is already approaching their practical limit. Further increase in the efficiency of $\mathrm{c}-\mathrm{Si}$ cells is possible in case of integrating into the tandem structures. For the construction of a tandem system, in which a solid c-Si solar cell is used as bottom element, we need partially transparent SC as a top device, through which with minimal losses passes a certain part of the solar spectrum, corresponding to the of optical absorption characteristics of the bottom cell.

Extensive possibilities for the design of tandem cells are associated with the recent appearance of effective thinfilm transparent cells based on organic materials, DSCs and PSCs. PSCs opened a new promising research area, focused on the development and study of different configurations for tandem structures on their basis. The best results to-date are obtained using so-called 4T-configuration in the four-terminal tandem perovskite-silicon solar cell PSC/c-Si [24]. Fig. 10 demonstrates the difference between the two-terminal and four-terminal configurations used for construction of tandem perovskite-silicon solar cells.

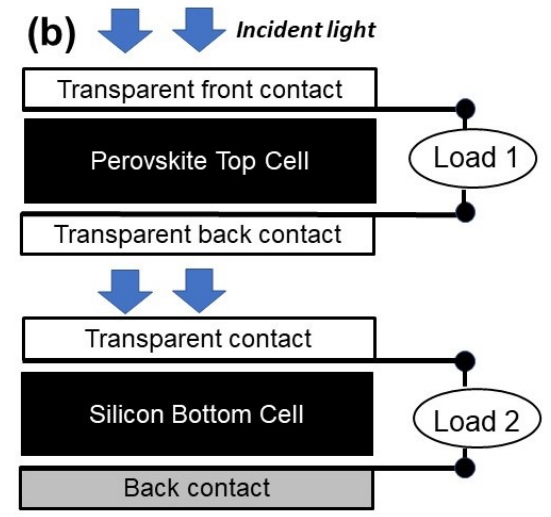

FIG. 10. Monolithic two-terminal (a) and four-terminal (b) tandem perovskite-silicon solar cells

While PSCs show the efficiencies exceeding $20 \%$, the combination of the overlapping optical absorption areas for PSC and c-Si elements, which possess, respectively, a width of $1.6 \mathrm{eV}$ (PSC) and $1.1 \mathrm{eV}$ (c-Si) opens a possibility of obtaining in this configuration the efficiency of tandem PSC/c-Si cells exceeding $30 \%$ [82]. A number of papers describe the effective PSC/c-Si tandem solar cells. The design of such a tandem may use one of two possibilities. The first one can concerns the design of monolithic SC based on the so-called two-terminal tandem solar cell, where the top PSC is formed directly on the surface of the bottom c-Si SC, and its top electrical contact serves as both a bottom contact for the whole device (Fig. 10b) [36,37]. In this configuration, the electrodes of both tandem elements are sequentially connected [81].

The monolithic two-terminal tandem cell has certain advantages, as it has only two output electrodes. However, from our point of view, the monolithic system possesses one fundamental flaw inherent in its scheme. When constructing any type of monolithic two-electrode tandem SC, either with a parallel or with a series connection of the individual elements, the main technical problem is to adjust their output electrical parameters (either by voltage or by current), which should provide the optimal parameters of $\mathrm{I}-\mathrm{V}$ characteristics of the device to achieve the maximum efficiency under AM1.5G. However, with decreasing the illumination levels the efficiency of a two-terminal device may drop due to the disproportionate deviation of the parameters for each cell.

These problems can be solved be using the so-called four-terminal solar cell, in which the two elements are combined not electrically, but "mechanically stacked", i.e. have a common optical circuit, while their electrical contacts are not connected to each other [83]. It is implied that the electrical power is generated by the top and bottom elements independently. The generated power is then transferred to the electronically controlled device, the task of which is to 
adjust their output parameters (Fig. 10a). The power consumed by such an electronic converter is negligible and will not result neither in the power losses nor in the efficiency of the entire solar cell system.

\section{Conclusion}

In this review, we focused on the latest achievements in the construction of the efficient PSCs and described new trends in perovskite solar photovoltaics, including the development of high-performance perovskite-silicon tandem solar cells, inorganic PSCs with stabilized efficiency and a new generation of PSCs for low lighting conditions that opens great possibilities for indoor applications. Special attention was paid to the development of new types of efficient photoelectrodes for PSCs based on very large band gap metal oxides.

\section{Acknowledgements}

The author gratefully acknowledges the support from the Russian Foundation for Basic Research by grant No. 1918-50429.

\section{References}

[1] Yin J., Molini A., Porporato A. Impacts of solar intermittency on future photovoltaic reliability. Nature Communications, $2020,11,4781$.

[2] Shi Z., Jayatissa A.H. Perovskite solar cells: from the atomic level to film quality and device performance. Materials, 2018, 57, P. 2554-2569.

[3] Kojima A., Teshima K., Shirai Y., Miyasaka T. Organometal halide perovskites as visible-light sensitizers for photovoltaic cells. J. Am. Chem. Soc., 2009, 131, P. 6050-6051.

[4] Kim H.S., Lee C.R., et al. Lead iodide perovskite sensitized all-solid-state submicron thin film mesoscopic solar cell with efficiency exceeding 9\%. Sci. Rep., 2012, 2, 591, P. 1-7.

[5] Burschka J., Pellet N., et al. Sequential deposition as a route to high-performance perovskite-sensitized solar cells. Nature, 2013, 499, P. 316319.

[6] Im J.H., Lee C. R., et al. 6.5\% efficient perovskite quantum-dot-sensitized solar cell. Nanoscale, 2011, 3, P. 4088-4093.

[7] Lee M.M., Teuscher J., et al. Efficient hybrid solar cells based on meso-superstructuredorganometal halide perovskites. Science, 2012, 338, P. 643-647.

[8] Ahn N., Son D.-Y., et al. Highly reproducible perovskite solar cells with average efficiency of $18.3 \%$ and best efficiency of $19.7 \%$ fabricated via Lewis base adduct of lead(II) iodide. J. Am. Chem. Soc., 2015, 137, P. 8696-8699.

[9] Park N.-G. Research direction toward scalable, stable, and high efficiency perovskite solar cells. Adv. Aenerg. Mater., 2019, 13, 1903106.

[10] Jeon N.J., Noh J.H., et al. Solvent engineering for high-performance inorganic-organic hybrid perovskite solar cells. Nat. Mater, 2014, 13, P. 897-903.

[11] Kim H.S., Lee C.R., et al. Lead iodide perovskite sensitized all-solid-state submicron thin film mesoscopic solar cell with efficiency exceeding 9\%. Sci. Rep., 2012, 2, 591.

[12] Song Z., Watthage S.C., et al. Pathways toward high-performance perovskite solar cells: review of recent advances in organo-metal halide perovskites for photovoltaic applications. J. Photon. Energ., 2016, 6, 022001.

[13] Nazeeruddin M.K., Snaith H. Methylammoniumlead triiodide perovskite solar cells: a new paradigm in photovoltaics. MRS Bulletin, 2015, 40, P. 641-645.

[14] Saliba M., Matsui T., et al. Cesium-containing triple cation perovskite solar cells: improved stability, reproducibility and high efficiency. Energ. Environ. Sci., 2016, 9, P. 1989-1997.

[15] Saliba M., Matsui T., et al. Incorporation of rubidium cations into perovskite solar cells improves photovoltaic performance. Science, 2016, 354, P. 206-209.

[16] Crystalline Silicon Photovoltaic Module Manufacturing Costs and Sustainable Pricing, URL: https://www.nrel.gov/docs/ fy19osti/72134.pdf.

[17] Shin S.S., Yeom E.J., et al. Colloidally prepared La-doped $\mathrm{BaSnO}_{3}$ electrodes for efficient, photostable PSCs. Science, 2017,356, P. $167-171$.

[18] Quiroz R.C.O., Shen Y., et al. Balancing electrical and optical losses for efficient 4-terminal Si-PSCs with solution processed percolation electrodes. J. Mater. Chem. A, 2018, 6, P. 3583-3592.

[19] Kumar M.H., Yantara N., et al. Flexible, low-temperature, solution processed ZnO-based perovskite solid state solar cells. Chem. Commun., 2013, 49, P. 11089-11091.

[20] Shi Z., Jayatissa A.H. Perovskite-based solar cells: a review of recent progress, materials and processing methods. Materials, $2018,11,729$.

[21] Cui, J., Yuan, H., et al. Recent progress in efficient hybrid lead halide PSCs. Sci. Technol. Adv. Mater., $2015,16,036004$.

[22] Yang W.S., Noh J.H., et al. High-performance photovoltaic perovskite layers fabricated through intramolecular exchange. Science, 2015, 348, P. 1234-1237.

[23] Shin S.S., Yeom E.J., et al. Colloidally prepared La-doped $\mathrm{BaSnO}_{3}$ electrodes for efficient, photostable PSCs. Science, 2017,356 , P. 167-171.

[24] Rohatgi A., Zhu K., et al. 26.7\% efficient 4-terminal perovskite-silicon tandem solar cell composed of a high-performance semitransparent perovskite cell and a doped poly-Si/SiO $x$ passivating contact silicon cell. IEEE Journal of Potovoltaics, 2020, 10, P. 417-422.

[25] Leo K. Perovskite photovoltaics: signs of stability. Nat. Nanotechnol., 2015, 10, P. 574-575.

[26] Burschka J., Pellet N., et al. Sequential deposition as a route to high-performance perovskite-sensitized solar cells. Nature, 2013, 499, P. 316319.

[27] Liu M., Johnston M.B., Snaith H.J. Efficient planar heterojunction perovskite solar cells by vapour deposition. Nature, 2013, 501, P. 305-398.

[28] Li X., Dar M.I., et al. Improved performance and stability of perovskite solar cells by crystal crosslinking with alkylphosphonic acid $\omega$ ammonium chlorides. Nat. Chem., 2015, 7, P. 703-711.

[29] Jeon N.J., Noh J.H., et al. Solvent engineering for high-performance inorganic-organic hybrid perovskite solar cells. Nat. Mater, 2014, 13, P. 897-903. 
[30] Ahn N., Son D.-Y., et al. Highly reproducible perovskite solar cells with average efficiency of $18.3 \%$ and best efficiency of $19.7 \%$ fabricated via Lewis base adduct of lead(II) iodide. J. Am. Chem. Soc., 2015, 137, P. 8696-8699.

[31] Park N.-G., Grätzel M., et al. Towards stable and commercially available perovskite solar cells. Nat. Energ., $2016,1,16152$.

[32] Jeon N.J., Noh J.H., et al. Compositional engineering of perovskite materials for high performance solar cells. Nature, 2015 , 517, P. 476-480.

[33] Yang W.S., Noh J.H., et al. High-performance photovoltaic perovskite layers fabricated through intramolecular exchange. Science, 2015, 348, P. 1234-1237.

[34] Nazeeruddin M.K., Snaith H. Methylammoniumlead triiodide perovskite solar cells: a new paradigm in photovoltaics. MRS Bulletin, 2015, 40, P. 641-645.

[35] Song Z., Watthage S.C., et al. Pathways toward high-performance perovskite solar cells: review of recent advances in organo-metal halide perovskites for photovoltaic applications. J. Photon. Energ., 2016, 6, 022001.

[36] Sahli F., Werner J., et al. Fully textured monolithic perovskite/silicon tandem solar cells with $25.2 \%$ power conversion efficiency. Nature Mater., 2018, 17, P. 820-826.

[37] Nogay G.,Sahli F., et al. 25.1\%-efficient monolithic perovskite/silicon tandem solar cell based on a p-type monocrystalline textured silicon wafer and high-temperature passivating contacts. ACS Energy Lett., 2019, 4, P. 844-849.

[38] Zhou Y., Zhu K. Perovskite solar cells shine in the "Valley of the Sun". ACS Energ. Lett., 2016, 1, P. 64-67.

[39] Schoonman J., Organic-inorganic lead halide perovskite solar cell materials: a possible stability problem. Chem. Phys. Lett., 2015, 619, P. 193-195.

[40] Akbulatov A.F., LuchkinS.Yu., et al. Probing the intrinsic thermal and photochemical stability of hybrid and inorganic lead halide perovskites. J. Phys. Chem. Lett., 2017, 8, P. 1211-1218.

[41] Adonin S.A., Froliva L.A., et al. Hybrid solar cells: antimony (V) complex halides: lead-free perovskite-like materials for hybrid solar cells. Adv. Energy Mater, 2018, 8, 1870026.

[42] Swarnkar A., Marshall A.R., et al. Quantum dot-induced phase stabilization of $\alpha-\mathrm{CsPI}_{3}$ perovskite for high-efficiency photovoltaics. Science, 2016, 354, P. 92-95.

[43] Spurgeon S.R., Du Y., et al. Competing pathways for nucleation of the double perovskite structure in the epitaxial synthesis of La ${ }_{2} \mathrm{MnNiO}_{6}$. Chem. Mater., 2016, 28, P. 3814-3822.

[44] Sheikh M.S., Ghosh D., et al. Lead free double perovskite oxides $\mathrm{Ln}_{2} \mathrm{NiMnO}_{6}$ ( $\mathrm{Ln}=\mathrm{La}$, Eu, Dy, Lu), a new promising material for photovoltaic application. Mater. Sci. Eng. B, 2017, 226, P. 10-17.

[45] Lan C., Zhao S., et al. Investigation on structures, band gaps, and electronic structures of lead free $\mathrm{La}_{2} \mathrm{NiMnO}_{6}$ double perovskite materials for potential application of solar cell. J. Alloy. Compd., 2016, 655, P. 208-214.

[46] Sheikh M.S., Sakhya A.P., et al. Light induced charge transport in $\mathrm{La}_{2} \mathrm{NiMnO}_{6}$-based Schottky diode. J. Alloy. Compd., 2017, 727, P. $238-245$.

[47] Barbosa D.A.B., Lufaso M.W., et al. Ba-doping effects on structural, magnetic and vibrational properties of disordered La $2 \mathrm{NiMnO}_{6}$. J. Alloy. Compd., 2016, 663, P. 899-905.

[48] Montcada N.F., Marín-Beloqui J.M., et al. Analysis of photoinduced carrier recombination kinetics in flat and mesoporous lead perovskite solar cells. ACS Energy Lett., 2017, 2, P. 182-187.

[49] Zhang N., Chen D., et al. Enhanced visible light photocatalytic activity of Gd doped $\mathrm{BiFeO}_{3}$ nanoparticles and mechanism insight. Sci. Rep., 2016, 6, 26467.

[50] Freitag M., Teuscher, J., et al. Dye-sensitized solar cells for efficient power generation under ambient lighting. Nat. Photonics, 2017, 11, P. 372-378.

[51] Juang S.S.Y., Lin P.Y., et al. Energy harvesting under dim-light condition with dye-sensitized and perovskite solar cells. Frontiers in Chemistry, 2019, 7, 00209.

[52] Chen C.Y., Chang, J.H., et al. Perovskite photovoltaics for dim-light applications. Adv. Funct. Mater., 2015, 25, P. 7064-7070.

[53] Biswas S., Kim H. Solar cells for indoor applications: progress and development. Polymers, 2020, $12,1338$.

[54] Lim J., Kwon H., et al. Unprecedentedly high indoor performance (efficiency $>34 \%$ ) of perovskite photovoltaics with controlled bromine doping. Nano Energy, 2020, 75, 104984.

[55] Double-sided solar photoconverter (options). Varfolomeev S.D., Todinova A.V., Shevaleevskiy O.I. Patent. RU 2531768: MPK H01 L 31/04, 27.10.2014, Issue 30, P. 7.

[56] Mathew S., Yella A., et al. Dye-sensitized solar cells with 13\% efficiency achieved through the molecular engineering of porphyrin sensitizers. Nat. Chem., 2014, 6, P. 242-247.

[57] Saygili Y., Soberger M., et al. Copper bipyridyl redox mediators for dye-sensitized solar cells with high photovoltage. J. Am. Chem. Soc., 2016, 138, P. 15087-15096.

[58] Michaels H., Rinderle M., et al. Dye-sensitized solar cells under ambient light powering machine learning: towards autonomous smart sensors for the internet of things. Chem Sci., 2020, 11, P. 2895-2906.

[59] Sakamoto R., Katagiri S., et al. Electron transport dynamics in redox-molecule-terminated branched oligomer wires on Au(111). J. Am. Chem. Soc., 2015, 137, P. 734-741.

[60] Mathews I., King P.J., et al. Performance of III-IV solar cells as indoor light energy harvesters. IEEE J. Photovolt., 2016,6, P. $230-235$.

[61] Barber G., Hoertz P.G., et al. Utilization of direct and diffuse sunlight in a dye-sensitized solar cell-silicon photovoltaic hybrid concentrator system. J. Phys. Chem. Lett., 2011, 2, P. 581-585.

[62] Lechene B., Cowell P. et al. Organic solar cells and fully printed super-capacitors optimized for indoor light energy harvesting. Nano Energy, 2016,26, P. 631-640.

[63] Minnaert B., Veelaert P., et al. A proposal for typical artificial light sources for the characterization of indoor photovoltaic applications. Energies, 2014, 7, P. 1500-1516.

[64] Freunek M., Freunek M., Reindtl L.M. Maximum efficiencies of indoor photovoltaic devices.IEEE J. Photovoltaics, 2013 , 3, P. 59-64.

[65] Apostolou G., Reiders A., Verwaal M. Comparison of the indoor performance of 12 commercial PV products by a simple mode. Energy Science \& Engineering, 2016, 4, P. 69-85.

[66] Su T.S., Hsieh T.Y., et al. Electrodeposited ultrathin $\mathrm{TiO}_{2}$ blocking layers for efficient perovskite solar cells. Scientific reports, $2015, \mathbf{5}$, 16098.

[67] Murugadoss G., Mizuta G., et al. Double functions of porous $\mathrm{TiO}_{2}$ electrodes on $\mathrm{CH}_{3} \mathrm{NH}_{3} \mathrm{PbI}_{3}$ perovskite solar cells: enhancement of perovskite crystal transformation and prohibition of short circuiting. APL Materials, 2014, 2, 081511. 
[68] Kozlov S., Nikolskaia A., et al. Rare earth and $\mathrm{Nb}$ doping of $\mathrm{TiO}_{2}$ nanocrystalline mesoscopic layers for high efficiency dye sensitized solar cells. Physica status solidi A, 2016, 213, P. 1801-1806.

[69] Tsvetkov N., Larina L., Shevaleevskiy O., Ahn B.T. Electronic structure study of lightly Nb doped TiO 2 electrode for dye sensitized solar cells. Energ. Environ. Sci., 2011, 4, P. 1480-1486.

[70] Tsvetkov N.A., Larina L.L., et al. Design of conduction band structure of $\mathrm{TiO}_{2}$ electrode using Nb doping for highly efficient dye sensitized solar cells. Progress in Photovoltaics: Research and Applications, 2012, 20, P. 904-911.

[71] Kozlov S., Nikolskaia A., et al. Rare earth and $\mathrm{Nb}$ doping of $\mathrm{TiO}_{2}$ nanocrystalline mesoscopic layers for high efficiency dye-sensitized solar cells. Phys. St. Sol. A, 2016, 213, P. 1801-1806.

[72] Vildanova M.F., Kozlov S.S., Nikolskaia A.B., Shevaleevskiy O.I. Niobium-doped titanium dioxide nanoparticles for electron transport layers in perovskite solar cells. Nanosystems: Phys. Chem. Math., 2017, 8, P. 540-545.

[73] Shevaleevskiy O.I., Nikolskaya A.B., et al. Nanostructured $\mathrm{TiO}_{2}$ films with a Mixed Phase for Perovskite Solar Cells. Rus. J. Phys. Chem. B, 2018, 12, P. 663-668.

[74] Rath M.S., Ramakrishna G., Mukherjee T., Ghosh H.N. Electron injection into the surface states of $\mathrm{ZrO}_{2}$ nanoparticles from photoexcitedquinizarin and its derivatives: effect of surface modification. J. Phys. Chem. B, 2005, 109, P. 20485-20492.

[75] Bugrov A.N., Almjasheva O.V. Effect of hydrothermal synthesis conditions on the morphology of $\mathrm{ZrO}_{2}$ nanoparticles. Nanosystems: Phys. Chem. Math., 2013, 4, P. 810-815.

[76] Larina L.L., Alexeeva O.V., et al. Very wide-band gap nanostructured metal oxide materials for perovskite solar cells. Nanosystems: Phys. Chem. Math., 2019, 10, P. 70-75.

[77] Almjasheva O.V., Krasilin A.A., Gusarov V.V. Formation mechanism of coreshell nanocrystals obtained via dehydration of coprecipitated hydroxides at hydrothermal conditions. Nanosystems: Phys. Chem. Math., 2018, 9, P. 568-572.

[78] Choi Y., Kim C.U., et. al. Two-terminal mechanical perovskite/silicon tandem solar cells with transparent conductive adhesives. Nano Energy, $2019, \mathbf{6 5}, 104044$.

[79] Nikolskaia A.B.,Vildanova M.F., Kozlov S.S., Shevaleevskiy O.I., Two-terminal tandem solar cells DSC/c-Si: optimization of TiO 2 -based photoelectrode parameters. Semiconductors, 2018, 52, P. 88-92.

[80] Vildanova M.F., Nikolskaia A.B., Kozlov S.S., Shevaleevskiy O.I. Novel types of dye-sensitized and perovskite-based tandem solar cells with a common counter electrode. Technical Physics Letters, 2018, 44, P. 126-129.

[81] Wali Q., Elumalai N.K., et al. Tandem perovskite solar cells. Renewable and Sustainable Energy Reviews, 2018, 84, P. 89-110.

[82] Quiroz C.O., Shen, Y., et al. Balancing electrical and optical losses for efficient 4-terminal Si-perovskite solar cells with solution processed percolation electrodes. J. Mater. Chem. B, 2018, 6, P. 3583-3592.

[83] Jaysankar M., Filipic M., et al. Perovskite-silicon tandem solar modules with optimised light harvesting. Energ. Environ. Sci., 2018, 11, P. $1489-1498$. 